\title{
Editorial:
}

\section{Role of Telemedicine in Achieving Good Control of Chronic Disease}

\section{Michelle Abou-Jaoude ${ }^{1}$, Suzanne Minor ${ }^{1}$, Zeidan Hammad ${ }^{1}$}

${ }^{1}$ Florida International University, Herbert Wertheim College of Medicine

Chronic diseases are the leading causes of death and disability in the United States. More than 100 million Americans - 45\% of the population - have at least one type of chronic disease. Those diseases are responsible for two third of the deaths in the U.S. ${ }^{(1,2)}$ In an effort to serve underserved communities, the telemedicine program of the Florida International University (FIU) Herbert Wertheim College of Medicine (HWCOM) Green Family Foundation Neighborhood HELP (NHELP) home visit program installed a remote monitoring telemedicine equipment in some of the most needed patient homes.

They were identified as those with uncontrolled chronic diseases. A three-year relationship using telemedicine and home visits to enhance adherence and communication. Through consistent efforts and patient education, the patient learned to control his hypertension and diabetes. When I first stepped into the wall of heat emanating from the musty, cramped studio apartment, I did not know what to expect. The tradition of a "home visit" is a storied one that many might see as outdated in an era of high patient volumes.

However, as part of the NHELP Program, we were bringing this tradition back to understand our patients and the socioeconomic factors affecting into their decision-making process. Three years later, I have come to realize how much more we learned. Communication at every level proved to be a challenge. We learned about the pitfalls of language barriers from conducting visits in garbled mixes of French, Creole, and English. We found subtle differences in the reasons why our patients might not be taking medications. Sometimes he did not trust them or believe they were necessary, sometimes he misunderstood when to take them, and sometimes he simply could not afford them.

Over the visits, we began appreciating the positive changes that we could make. Simple things, like making visual aids for which medications should be taken and decluttering their diet went a long way towards his blood pressure control, which we could follow through telemedicine. Seeing him 
determined to carefully manage his own blood pressure is fantastic and reminds me that we have come a long way.

Mr. A, a 73-year-old, retired, Haitian male was living in an elderly living facility with a history of hypertension, type 2 diabetes, osteoarthritis, asthma, and a previous history of two strokes. He had no social insurance and very limited financial resources, causing him to sometimes sleep without eating. He was not fluent in English and therefore encountered communication problems in the community.

However, he had strong beliefs, attends church on weekly basis, and was always optimistic that God would guide and help him. In the beginning of 2013, Mr. A was selected to be part of our FIU HWCOM Telemedicine program. When we first met him, his blood pressure was uncontrolled and did not know how to monitor his blood sugar. In fact, the first time we visited him in his home, his blood pressure was 190/110. We prescribed him a new medication and helped him simplify his regimen. After the first month of treatment and monitoring, he was feeling much better, and his vital signs were well controlled; he had more confidence in himself. He stated that, since he became involved in telemedicine, he had more awareness about his illness and was more confident that he could stay healthy and have a better life.

The American Telemedicine Association defines telemedicine as "the use of medical information exchanged from one site to another via electronic communications to improve a patient's clinical health status." (3) Mr. A was taught over time to use his telemedicine unit to track his blood pressure and sugar. Such reporting may decrease errors in glucose monitoring. (4) Ongoing web seminar education via telehealth has been documented to improve adherence in patients using antihypertensives. $^{(5)} \quad$ Additionally, individualizing treatment plans via telemedicine may also improve adherence and decrease costs, as shown in one study with patients who suffered from inflammatory bowel disease. ${ }^{(6-11)}$

Telemedicine was the bridge for us, combining the traditional home visit with the digital age allowing us to individualize a treatment plan for Mr. A. The ability to follow his blood pressure and blood glucose regularly, without our physical presence, provided invaluable and detailed feedback. Weekly digital interaction afforded opportunities for us to practice patient education skills, as we worked with him to decipher the best way to navigate the 
workflow of the touchscreen console.

We quickly saw the drawbacks of complicating the interface especially given his poor English, he learned to problem solve with his input the best way for him to use the machinery. Through this process, we cleared out redundant medication bottles, simplified, optimized his medication regimen, and removed lisinopril from his home after he had an angioedema reaction to the drug. We learned that he became dizzy when he took his medication and thus only took it when he felt his blood pressure was too high. This had led to an ever-worsening cycle of the medical dose being increased and worsening dizziness with medication use.

One of the most important aspects of telemedicine was providing him a blood pressure cuff, which was the main tool he used to understand how medications were controlling his blood pressure. Telemedicine enhanced his self-awareness and empowered him to take control of his diabetes and hypertension management. We have seen firsthand how telemedicine can be a valuable tool towards improving adherence and patient-centered communication.

We may conclude that telehealth has opened a new frontier for health care in today's world. We can identify the roles that can be played by telehealth in improving communication, monitoring, educating, and increasing patient's compliance with medications.

Fund: This research received no specific grant from any funding agency in the public, commercial, or not-for-profit sectors.

\section{References}

1. Wu S, Green A. Projection of Chronic Illness Prevalence and Cost Inflation. RAND Corporation, October 2000.

2. Centers for Disease Control and Prevention. Chronic Disease Overview page.

http://www.cdc.gov/nccdphp/overview.h tm Accessed April 6, 2007

3. American Telemedicine Association. What is telemedicine? www.americantelemed.org/abouttelemedicine/what-is-telemedicine\#.VEAsfnF9yw (2012, accessed 10 Dec 2014).

4. Klonoff DC. Improved Outcomes from Diabetes Monitoring: The Benefits of Better Adherence, Therapy Adjustments, Patient Education, and Telemedicine Support. J Diabetes Sci Technol. 2012 May (accessed 10 Dec 2014); 6(3):486490.

www.ncbi.nlm.nih.gov/pmc/articles/PM C3440062

5. Santos MV, Oliveira DC, Novaes MA. A telehealth strategy for increasing 
adherence in the treatment of hypertension in primary care. Telemed $\mathbf{J}$ E Health. 2013 Apr (accessed 10 Dec 2014);19(4):241-7.

www.ncbi.nlm.nih.gov/pubmed/2350992 0

6. Hommel KA, Hente E, Herzer M, Ingerski LM, Densonb LA. Telehealth behavioral treatment for medication nonadherence: a pilot and feasibility study. Eur J Gastroenterol Hepatol. 2013 Apr (accessed 10 Dec 2014); 25(4): 469_ 473.

www.ncbi.nlm.nih.gov/pmc/articles/PM

C3703848/

7. Journal of the Association for Academic Minority Physicians: the Official Publication of the Association for Academic Minority Physicians, 31 Dec 1996, $8(1): 2-10$

PMID: 9048466

8. Farmer A, Gibson OJ, Tarassenko L, Neil A. A systematic review of telemedicine interventions to support blood glucose self-monitoring in diabetes. Diabet Med 2005;22:1372-1378

9. Jaana M, Paré G, Sicotte C. Home telemonitoring for respiratory conditions: a systematic review. Am J Manag Care 2009; 15:313-320

10. Shea S, Weinstock RS, Teresi JA, et al. A randomized trial comparing telemedicine case management with usual care in older, ethnically diverse, medically underserved patients with diabetes mellitus: 5-year results of the IDEATel study. J Am Med Inform Assoc 2009;16:446-456

11. Bashshur RL, Shannon GW, Smith BR, Alverson DC, Antoniotti N, Barsan WG, et al. The empirical foundations of telemedicine interventions for chronic disease management. Telemed $\mathrm{J} E$ Health. 2014;20(9):769-800. 